\title{
Quality attributes in the non-market stated- preference based valuation of cultural goods
}

\author{
Aleksandra Wiśniewska
}

To cite this article: Wiśniewska, A. (2019). Quality attributes in the non-market stated-preference based valuation of cultural goods. Central European Economic Journal, 6(53), 132-150.

DOI: 10.2478/ceej-2019-0012.

To link to this article: https://doi.org/10.2478/ceej-2019-0012 


\title{
Central European Economic Journal
}

\author{
Aleksandra Wiśniewska1 ${ }^{(i D)}$ \\ 1 Faculty of Economic Sciences, University of Warsaw, corresponding author: awisniewska@wne.uw.edu.pl
}

\section{Quality attributes in the non-market stated-preference based valuation of cultural goods}

\begin{abstract}
Evidence-based policies require well-established research and reliable data. One of the major difficulties in delivering such data for cultural policies lies in measuring culture, expressing its ephemeral nature in numbers and indicators, as research used to do in other sectors. Stated-preference based non-market valuation is one of the few tools able to reveal the benefits that cultural goods deliver to the society for cost-benefit analysis. The prevalent problem in this kind of studies is poorly defined, ambiguous goods. When attempting to define them, we cannot forget that the essence of art and culture, which is in itself worth measuring, is quality. The goal of the article was to review previous uses of quality measurements of arts and culture in stated-preference based non-market valuation research, most of which are dedicated to performing arts and cultural heritage.
\end{abstract}

Keywords: quality measurement, stated preferences, non-market valuation, performing arts, cultural heritage

JEL Codes: Z1, Z18, H44

\section{Introduction and literature selection}

Cost-benefit analysis has become a standard methodology for planning, optimising and evaluating public policies (Organisation for Economic Co-operation and Development, 2006; US Office of Management and Budget, 1992; O'Brien, 2010; Treasury, 2018). To conduct a cost-benefit analysis, we need to know the value of benefits. The non-market characteristics of many artand culture-related products and services, and the role of passive-use value in value creation in the cultural sector, incline one to the use of the stated-preference based non-market valuation. Best practices inform us that the questionnaire from which the data for this kind of research originate "must successfully convey the nature of the good [...] in a way that is plausible, understandable and meaningful to [the] respondent" (Carson, Flores, \& Meade, 2001, p. 178). The delivery of the precise description of the good to be valued is a vital issue to assure the reliability of non-market valuations of cultural goods. What we need, therefore, is information: "It is well known that the amount of information provided to respondents in CVM [contingent valuation method] has a critical effect on their WTP [willingness to pay] judgements, with the general assumption being that better-informed judgements are more useful than ill-informed ones" (Throsby, 2003, p. 3).

Poorly defined, ambiguous goods are a prevalent problem in non-market valuation in cultural economics (Noonan, 2003). People are often not familiar with cultural goods (Frey, 2003). According to methodological requirements, goods to be valued should be measurable and preferably expressible in monetary terms. However, many cultural goods cannot even be commoditised hypothetically. Randall, Ives and Eastman noticed that "the nature of some goods is such that increases in quantity provided are not purely quantitative increases, but lie more in [the] nature of improvements in quality" (1974, p. 133). Their case study, damages associated 
with Four Corners power plant and Navajo mine in the US, comes from environmental economics, from which non-market valuation originated. However, the problem occurs when aesthetics come to the fore (the main problem discussed is air pollution that decreases landscape visibility). The challenge of measuring qualitative rather than quantitative characteristics is even more applicable to the arena of art and culture.

Performance quality characteristics turned out to be major determinants of demand for performing arts and their valuation based on consumer preferences. In the demand model based on existing data from three theatre companies in Sydney, Throsby (1990) found that price coefficients were insignificant in two out of the three theatres studied, with an unexpected positive coefficient for the remaining one, a result much weaker than for quality characteristics. Definitively, Throsby also determined that survey-based utility estimation shows that quality characteristics influence demand much more than price does (p. 174). Additionally, the price of substitutes and the cost of time also turned out to be less significant than quality characteristics within the theatre market (Krebs \& Pommerehne, 1995).

In early literature, the quality of cultural heritage was indicated as an important factor in its value (Martin, 1994). However, the quality of cultural heritage is usually stated and does not change over time; Stonehenge remains the same object as it was at the time of its creation, and objects documented in the British Museum have remained the same since they were created. Once given, cultural heritage is a subject of conservation or restoration. Therefore, the quality discussed in nonmarket valuation studies devoted to cultural heritage refers to the quality of the provision or experience of the goods rather than to the quality of the goods itself.

In this article, I review the historical uses of quality measurements of arts and culture in stated-preference based non-market valuation research. I focus on non-market valuation studies devoted, first, to the performing arts and, second, to cultural heritage, two traditional fields of research for cultural economics. Additionally, I also include studies within the broader field of the valuation of art and culture.

Articles for this review came from a few sources. First, I identified the articles from previous meta-analysis or bibliographies (Noonan, 2002, 2003). I was interested only in scientific articles published and available online that included empirical use of stated preferences (SPs). Policy reports, working papers and studies published only in books were excluded from the review. It limits the scope of this revision importantly. For comparison, there is only one such article among nine entries in bibliography of contingent valuation $(\mathrm{CV})$ studies in theatre annotated by Noonan (2002). Second, I searched for culturerelated passwords (e.g. "culture", "theatre", "heritage", "museum", "performing", "art") in comprehensive bibliography of CV by Carson (2011). ${ }^{1}$ Again, only scientific articles available online were chosen. Additionally, I searched also for more recent studies using Google Scholar and checked scientific journals where non-market valuations of culture used to appear including Journal of Cultural Economics, International Journal of Cultural Policy and Journal of Cultural Heritage.

Art critics, philosophers and artists, not to mention the public, have debated and experienced the issue of defining the quality of art and culture for centuries. To avoid sinking into the depths of theoretical debate, I use the term "quality" according to its uses in cultural economics. In this article, the quality of art and culture is what cultural economists measure when they claim that they measure quality. ${ }^{2}$ Owing to the preference-based methods used in the studies documented in this review, quality is usually discussed from the point of view of the audience and general public. If these studies are to serve evaluation of cultural policy, the quality needs to be expressed in a way that is feasible for policy-makers. Therefore, the quality discussed has to have [1] roots in what people feel fine art and culture is and [2] the potential for objectification. ${ }^{3}$

1 All meta-analysis and bibliographies considered focus on CV, one of the methodologies used within stated-preference based nonmarket valuation. Although today the use of choice experiments (CE) is comparable, in the moment Noonan $(2002,2003)$ were collected, CE was only emerging (see Section 2.1.). For Carson (2011), CE is just one of preference elicitation format included in his bibliography.

2 "Now what do the words of this language signify? - What is supposed to shew what they signify, if not the kind of use they have?". According to Wittgenstein, the only way to explain the notion of a term is to show how the term can be used in different contexts. Any philosophical or metaphysical concept would not be able to reveal more about the sense of the term than the ways we try to use it in natural language (Wittgenstein, 1958, note 10, p. 6)

3 However, "essentially, all attempts to operationalize the objective perception of quality have failed" (Bille \& Olsen, 2018, p. 238). 
Every article considered in this review was inspected towards the use of quality characteristics or measurements. Some of the articles did not include quality of cultural goods and services into the empirical research (e.g. Báez \& Herrero, 2012; Bedate, Herrero, \& Sanz, 2009; Papandrea, 1999; Snowball, 2005); however, some discuss it theoretically (Bille Hansen, 1997; Mazzanti, 2002). Both types were excluded from the review. Furthermore, literature reviews and citations of non-market valuations revealed comparably extensive usage of quality measurements in demand studies, particularly in the field of performing arts. They complement the literature selection.

Finally, this review is based on 35 case studies: 19 about performing arts (mostly theatres) and 13 about cultural heritage (including historical sites, archaeological sites and museums), followed by three additional articles from the other fields of culture. This selection differs significantly from previous reviews. Overwhelming part of the bibliography of CV studies in the arts and culture (Noonan, 2002; includes 108 positions) refers heritage case studies with only three cases of performing arts. This difference seems to mirror more developed reflection about the quality in the field of performing arts, supported by tradition of critics that contribute to theatre and music circles. As noted above, in case of cultural heritage, authors discuss rather the quality of provision or experience rather than cultural goods itself, what might indicate that the problem of expressing quality of cultural goods is more severe in the case of performing arts, where the challenge lies in defining the quality of art itself. Importance of performing arts' case studies in this review has expression in the length and detail of section devoted to performing arts in the following sections.

The paper delivers a better understanding of what can be called the "quality of art and culture" in economics studies and how, if at all, it can be operationalised to provide reliable data for cultural policies. If successful, it is hoped that the achievements in one methodology of research can be utilised in studies conducted elsewhere. In the next section, stated-preference based non-market valuation is presented as a tool for research-based cultural policy. Section 3 delivers the review of the usage of quality measurements in the economics of performing arts, in the economics of cultural heritage and in the remaining fields of cultural economics and cultural policy. The paper concludes with a summary and several recommendations for future research.

\section{Stated-preference based valuation as a tool for cultural policies}

\subsection{Non-market valuation}

The challenge is to choose a tool for evidence-based cultural policies that is sound, theoretically structured, scientifically proven, as well as relevant to cultural policy-making operations (Mazzanti, 2003, p. 551; Mourato \& Mazzanti, 2002). The choice could have farreaching consequences, as "once something has been quantified, the figures tend to become 'truths'" (Bille \& Olsen, 2018, p. 244).

Although the value of culture has many dimensions (symbolic, societal, cultural, among others; see Throsby (2001) for an extended summary), its economic value has gained a level of interest surrounding its expression in monetary terms that is potentially comparable with expenditures on culture. The cultural circles used to react to economic valuations of culture with anxiety and hesitation. However, avoiding economic valuation diminishes the likelihood that the value of culture will be considered in economic decision-making, which is crucial for the cultural sector that is highly dependent financially on public support, at least in Europe. As Bakhshi, Fujiwara, Lawton, Mourato and Dolan (2015, p. 2) state, the "Robust valuation of cultural goods and services [...] allows cultural institutions to demonstrate in quantitative terms the value that they create for society".

Economic value is not equal to market value. Cultural goods and services have characteristics of a public good. The view of a picturesque castle on the hill is non-rival in a sense that the experience of this view gained by an individual does not reduce the benefits of other viewers; it is non-excludable as nobody can prohibit looking and there is no reasonable way to price it. When cultural goods and services only partially share these characteristics, we place them in the category of mixed goods, together with health care or education, 
which can be the subject of market exchange, but are often provided by the public sector. Throsby (1994, p. 9) described culture as mixed goods: "joint production of a private-good component enjoyed by individual attendees and [a] public-good component deriving from the value of the arts and culture to society at large". There is also broad evidence for the dual nature of cultural goods in aesthetic literature with very early distinctions made between the value arising from the disinterested experience of beauty and the value from objects that serve the self-love of individuals (Hutter \& Throsby, 2008, p. 2). Cultural institutions are often freely (or somewhat cheaply) accessible with nominal fees (not related to the true costs of producing and providing cultural goods). Therefore, the observation of market transactions does not give a full insight into people's choices. Conversely, this is possible if a non-market valuation method is used.

There is a growing literature examining whether nonmarket valuations aimed at eliciting people's preferences over cultural goods is relevant to cultural policymaking. According to the rule of consumer sovereignty - and a crucial idea behind these studies - governmental expenditures borne by people (i.e. through taxes that public budget consists of) are justifiable if they do not exceed the benefits gained by them as a result of these expenditures. In the context of cultural heritage policymaking, Mazzanti (2003, p. 552) stated that: "[Valuation] matters to the extent that assessing and comparing the political jurisdiction with the economic jurisdiction is relevant $[\ldots]$ where the political jurisdiction is the level of government making the provision of the good (local, regional, national, global), and the economic jurisdiction includes all individuals receiving the cultural heritage benefits". The aim of non-market valuations is not to find an "optimal" equilibrium of supply and demand in the cultural market; instead, they only measure the benefits connected to a possible situation in this market in respect of the current status quo.

\subsection{Stated-preference based methods}

Benefits provided by non-market goods are usually divided into use (direct) and passive-use (non-use) values. The term "passive-use value" was first used to encompass different concepts of value that people can assign to goods even though they do not use them in a direct way (in the 1989 American court decision; Carson, 2011). The idea came from environmental economics, starting with an early article by Krutilla (1967), and was used to indicate that it is not only visitors (users) who benefit from nature.

The passive-use value of culture and performing arts in particular was noticed in early studies of cultural economics; however, it is sometimes mixed into the external effects literature. Throsby and Withers (1979) identified "option demand" - the source of option value gained by people who "wish to retain the option of attending the performing arts even if they do not at present attend" (p. 170) - and 'collective benefits' namely, "[the] provision of public creative ideas and aesthetic standards, social improvement of participants themselves, development of national feeling and identity, provision of social comment and criticism" ( $p$. 176) - both discussed as passive-use value sources (see Throsby, 2001). Morrison and West (1986) investigated the nature of the benefits that the inhabitants of Ontario, Canada, experienced from performing arts, even as nonusers. They identified option value ("anticipated future use") and passive-use value (e.g. "welfare of future generations"). Bille Hansen (1997) found out that the total value of Royal Theater in Copenhagen (performing arts institution as well as a cultural heritage object) to the Danish people consists of use value (private consumption) only in $7 \%$, what indicates the importance of passive-use value in culture. While culture generates both use and passive-use values, the aim of the valuation tool in question is to capture both.

Non-market valuation techniques have been being developed within the microeconomic framework since the 1960s in response to problems with estimating the benefits gained by the consumers of public and mixed goods. These methods can be divided into two categories with respect to the type of data analysed: revealed preferences (RPs; actual choices made by consumers in the market - what people do) and SPs (declared choices that would have been made by a consumer in a hypothetical situation described in a questionnaire what people say they would do).

SP based non-market valuation tools enable the researcher to learn about passive-use values, one of its biggest advantages (Carson, 2011); it is a way to measure 
what was previously considered to be unmeasurable. SP studies deliver the possibility of valuing hypothetical situations that are not yet available to consumers, which is a common situation when dividing public resources between cultural institutions; decisions are made $e x$ ante on the basis of hypothetical cultural programmes. Moreover, SP-based valuations offer relative ease in gathering proper data, directing monetary valuations and straightforward aggregation across individuals (Carson, 2012; O'Brien, 2010).

SP methods are well established in economics. Guidelines for quality research have been being developed for decades (Arrow et al., 1993; Bateman etal., 2004; Champ, Boyle, \& Brown, 2003; Hensher, Rose, \& Greene, 2005; Hess \& Daly, 2014; Kanninen, 2007) and are employed in thousands of applications (Carson, 2011). However, some biases can still affect the results. Hypothetical biases point out potential over- or understatements of individuals' true preferences in the hypothetical situations a respondent reacts to. Embedding and scope effects indicate that the scope of change, which matters for real-life cost decisions, can be omitted in hypothetical situations: financing additional annual temporal exhibitions can be valued differently when presented alone or as part of a broader cultural programme. People's responses can also differ according to the payment mechanism introduced in hypothetical scenarios (whether it is an additional tax or a voluntary payment).

In surveys investigating the need for this kind of valuation, respondents are asked how much they are willing to pay for a given good treated as an "indivisible whole" (in this case, the method is called CV) or choose the preferred option from a given set of choices (choice experiment [CE]). CE is currently getting increasingly popular within the literature (Carson, 2011; Lloyd-Smith, Zawojska, \& Adamowicz, 2018) as it overcomes some of the problems of $\mathrm{CV}$. It avoids the explicit elicitation of willingness to pay (WTP) and diminishes the exposition of the respondent to monetary issues, underlining other characteristics of a good. It also limits the starting point bias that appears in CV studies where any value is indicated as a reference and 'protest zeros' (refusal to pay anything for the hypothetical programme because of a general dislike of paying higher taxes or other aspects that are not directly connected with an evaluated good; Snowball, 2008; Tuan \& Navrud, 2007).
$\mathrm{CE}$ allows researchers to value not only the single good (a 'holistic' evaluation) but many attributes of a good described as a bundle of characteristics, which is in line with the theory of goods by Lancester (1966). It gives insight into trade-offs and the weights attached to the components of the value derived from different attributes (Mazzanti, 2002, p. 546). The description of an art piece as a bundle of its characteristics is a common feature of both economic and aesthetic theories. In the field of aesthetics, the roots of this concept lie in Aristotle's definition of tragedy, more recently continued by Beardsley (1958) and Dickie (1988; see also Ginsburgh \& Weyers, 2008). Moreover, respondents who choose the most preferred alternatives in sequences of choice tasks deliver a large amount of preference information from an individual, thus reducing the sample size needed.

The non-market valuation of cultural goods has been gaining interest since the 1980s. However, studies of cultural resources are only a small fraction of the entire bibliography of non-market valuation studies, more often used for the purpose of evaluating economic policies in environmental, transportation, outdoor recreation and health arenas (see Carson, 2011 for comprehensive bibliography). CV has been employed to the broadest extent. In 2003, Noonan (2003) depicted 65 original studies' states that have been conducted since 1972. Mazzanti (2003) indicated that at that point in time, there existed no application of $\mathrm{CE}$ in respect of cultural goods; a number appeared in subsequent years (Choi, Ritchie, Papandrea, \& Bennettet, 2010; Morey \& Rossmann, 2003; Willis \& Snowball, 2009; Grisolía \& Willis, 2012, 2016, 2011; Wiśniewska \& Czajkowski, 2017). A growing number of CE studies in economic literature should be treated as a forecast of the further development of non-market valuations within cultural economics.

\section{Quality characteristics of culture}

\subsection{Quality characteristics of performing arts}

There are a few SP-based non-market valuations of performing arts alone. Instead, demand studies provide a broader range of quality measurements in the field 
of the economics of performing arts. The division of studies devoted to demand and valuation is weak; a few studies present a data collection method and estimation techniques typical of non-market valuations, limiting the results to the analysis of the characteristics of demand without expressing the economic value of the performing art piece or institution examined. The following literature review contains both valuation studies and demand studies. Quality measurements derived from supplyside data are presented first, followed by expressions of subjective perception (derived from reviews and word of mouth) and attributes mostly based on a simple division into art genres.

\subsubsection{Supply-side features}

One of the ways to express quality in the economics of performing arts is to use supply-side features: expanses on different elements of a performance and labour involvement, as well as a compilation of repertoire of one's own and guest performances. Zieba (2009, 2011) and O'Hagan and Zieba (2010) tested variables created with the use of production data for theatres in Germany, Austria and Switzerland. "Cast size" achieves the most stable results and was also used by Werck and Heyndels (2007), resulting in similarly significant and positive effects on demand. Professionalism also plays a positive role for the audience in comparison to the amateur background of performers (Willis \& Snowball, 2009). The statistical significance of the "technical ability of artists" (measured in expenditures on artistic personnel per artist), "technical standard of design" (expenses of décor and costumes per production divided by the number of artists employed) and "theatre reputation" (the share of guest performances in repertoires) differ from study to study.

As Zieba (2009) explained, supply-side data-based variables are not necessarily related to the quality of a performance. Modest monodrama is obviously characterised by its low expenditure on artistic personnel and physical productions whilst retaining high artistic quality. Tobias (2004) confirmed this observation; he found that inputs (capital and labour) can only shape the merit of performing arts productions (measured by the aggregated expert opinion) in some market sectors (opera and ballet, but not theatre) and only to some degree. Moreover, the assumed positive effect of including guest performers in repertoire is questionable. Their role highly depends on the organisational features of the venue. Audiences of repertory theatres often assign value to the venue in relation to in-house productions that dominate in repertoire. Colbert, Beauregard and Vallée (1998) found a significant and positive effect of the willingness to raise subscription prices by $5 \%$ for in-house productions. On the other hand, specialisation within guest performances reveals little about the quality of shows presented, thus potentially indicating the commercial characteristics of the venue (the case of Broadway) and resulting in higher demand (Urrutiaguer, 2002).

Colbert et al. (1998) and Krebs and Pommerehne (1995) used the length of staging (whether the performance was shorter or longer than the average or a given threshold) as a proxy of success in the general appeal of performances. Authors of latter studies therefore assume that popular performances (being staged for long periods of time with commercial success) provide low artistic quality, while answering lowbrow taste.

\subsubsection{Perception of quality}

Performing art pieces are experience goods; therefore, their quality is unknown before they are experienced. The perception of performance expressed in reviews, word of mouth and recognising artists involved in the production (the author, the play itself, director or producer and cast, whether they are known or unknown) is important for potential viewers regarding uncertainty connected with a visit to the theatre. Therefore, expressions of the perception of quality were often considered to be "quality variables" in previous research, with significant results. However, they are indicators of performances' merit content rather than merit characteristics themselves. Reviews were a method of evaluating a performance's standard (its source material, production, acting and design valued on a fivelevel scale from very poor to very good) included in a study of box office theatre data in Sydney (Throsby, 1990). Furthermore, the recognition of the author as an overall 
measure of the standard of the performance turned out to be significantly important for demand. A Turkish study provided additional information concerning the importance of authors' recognition, specifically in less developed cities (Akdede \& King, 2006). Abbé-Decarroux (1994) illustrated that positive reviews (valued on a sixlevel scale), as well as the recognition of a broader group of creators (the author as well as the cast and producer), play a vital role in limiting the uncertainty of the quality of the performance and therefore increase its demand. Corning and Levy (2002) confirmed the positive impact of reviews, and Willis and Snowball (2009) confirmed the positive effect of the recognition of the director and producer in the South African context.

The use of ex-post opinions (of experts or viewers in general) in SP-based non-market valuation studies devoted to hypothetical (ex ante) experiences is questionable. Grisolía and Willis $(2011,2012)$ tried to include reviews and "word of mouth" as attributes of theatre performances to be valued in $\mathrm{CE}$; the authors investigated how they impact the WTP for performances in the Northern Stage theatre in Newcastle-uponTyne. They constructed four levels of both attributes ("average", "very good" and "must-see", with "poor" as a base level). Reviews, as well as word of mouth, turned out to be highly significant; the more positive the opinion, the higher the WTP. The result is not surprising. It reveals that people are of the view that they prefer to see what is found to be positive by experts and viewers in general. Social desirability bias can impact this result significantly (Schwarz \& Sudman, 1992). A study by Throsby (1990) shared the same problems; in a valuation study based on a survey among the audience run in the form of a CE, Throsby used simple merit attributes of performances: appeal and overall standard, both with three levels of attributes ("of little interest", "moderately interesting" and "extremely interesting" for appeal; "poor', "average' and "excellent' for standard) and both being statistically significant. The difference in changing the level of appeal from low to high is three times higher than lowering the price from high (15 AUD) to low (5 AUD), therefore demonstrating the importance of perceived quality. However, its value as a "quality food" for policy-making is limited. People are willing to pay for performances that will gain their interest. The opposite result would be extremely surprising. Nevertheless, how can decision makers know what people are interested in regarding performing arts?

Moreover, the impact of reviews in real-life situations can be much more complicated than the preferences revealed in the course of a hypothetical scenario. Inclusion of opposing opinions in the reviews was identified as the reason for the low statistical significance of the variables used in studies examining theatre demand with the use of existing data. Deeper insight shows that the impact of reviews depends on the high- or lowbrow tastes of the audience. Urrutiaguer (2002) was heavily invested in discovering a method of aggregating the evaluation of performances hidden in reviews. He assumed that reviewers prefer highbrow repertoire. Highbrow repertoire receives more reviews, and so highbrow performance audiences take them into account. At the same time, however, we observed theatres (presenting lowbrow repertoire presumably) where negative reviews (or the lack of them) indicated a higher demand. Bille and Baldin (2017) showed that expert evaluation is not correlated with audiences' evaluation. They proceeded in opposing directions and so "performances particularly liked by the reviewers are definitely not the same performances as the ones liked by the audience" (p. 6). What is more, the percentage of seats occupied in the Royal Theatre in Copenhagen increases together with the audiences' positive evaluation, but remains independent of reviews.

\subsubsection{Type of performance}

Baumol and Bowen (1966) undertook the first economic study of performing arts by dividing them into art forms: theatre (divided further into Broadway, off-Broadway and regional theatres), symphony, opera and dance. Morrison and West (1986) followed a similar attitude in an early study of the economic valuation of the art. They investigated the performing arts sector by dividing it into theatre, opera and ballet. Throsby and Withers (1979) described the economics of performing arts with the use of Australian data, enabling (and requiring) the division of the performing arts market into theatre (drama), symphony (music), opera and ballet. The taxonomy of types of performances differs from study to study. It is highly contingent on the site and time of 
a research study and the level of observation (whether it is the whole performing arts institution, a particular title or performance or the individual artistic experience itself). "Repertoire classification", "genre" and "type of a play" are terms used interchangeably to indicate similar taxonomies based on two sources of information: the time in which the play was written and the general drama classification rooted in an ancient division into tragedy and comedy. Table 1 shows the different meanings of these categories and their inner taxonomy in literature.

Taxonomy based on the time in which the play was written turned out to be insignificant in most of the cases, at least for some of the theatres included in the research, e.g. in the analysis of a South African performing arts festival (Willis \& Snowball, 2009). Plays written before 1900, "classics", turned out to be the preferable choice of audiences only in one out of the three theatres in Sydney examined by Throsby (1990) and remained insignificant in the remaining theatre. ${ }^{4}$ Abbé-Decarroux (1994) created a repertoire classification of performances in one of the biggest theatres in Geneva, according to the period in which the play was written, as well as factoring in whether the author was alive or deceased. His results are similarly weak. Coefficients for modern and contemporary plays are insignificant (classic plays being the base level), with only "atypical plays" influencing theatre attendance.

In some cases, taxonomies are developed by the surrounding cultural context: the language of the play or the place of the author's origin. Urrutiaguer (2002) added a division into French and foreign plays in a study focussed on public French theatres. The significance of the repertoire classification differs between theatres in which the audience's opinions go in line with those of critics (the play being in a foreign language is a negative indicator for demand) and those where the audience does not share the judgements of reviewees (classics raise demand, while contemporary French plays decrease it). Authors with Flemish origins, as well as the author's age, turned out to be insignificant for demand in Flemish theatre; however, plays spoken in Flemish or Dutch positively influenced demand

4 Not all types of repertoire described by Throsby (1990) appear in all theatres under question; e.g. plays written before 1900 appear in repertoire of two out of three venues only.
(Werck \& Heyndels, 2007). The author's nationality had no significant impact on the quantity of tickets sold in the Turkish public theatre (Akdede \& King, 2006). Plays set in a South African context increased the utility driven from performances presented in the National Arts Festival in South Africa compared to those set in a "Western" (or similar) context (Willis \& Snowball, 2009).

Simple drama classification rooted in the division into tragedy and comedy remains the most significant within the extant literature and is commonly used in $\mathrm{CE}$ in the field. Historical division into tragedy and comedy is, of course, not sufficient. First of all, it seems that we experienced a shift in the meaning of the term "drama": in literature studies, this term describes a genre of literature without indicating anything about content, yet in a common speech drama is connected to something sad and comedy to something happy. Moreover, there are some performances that are difficult to assign to a simple happy/sad distinction, and it is probably the reason for the inclusion of additional types of plays in the studies.

Willis and Snowball (2009) included "musical" as a base level, thus lowering the utility of the audience compared with comedies (no significant difference between dramas and musicals was noted). Corning and Levy (2002) added "Shakespeare" and "Tommy" categories to indicate performances based onShakespeare plays and an annual highlight of the three theatres of The Pacific Conservatory of Performing Arts, USA, unveiling the strong single-institution context of the study. The preference for "Tommy" among subscribers is evident in two of the venues, while the other findings differ between theatres with no significant evidence for the preference of any genre in Severson Theatre. The "Royal Shakespeare Company" category, included by Grisolía and Willis (2016) as one of their "context" variables (together with the time of origin: before or after 1900), underlines the problem with a strong preference towards Shakespeare among British audiences. The "comedy involving music and dance" category used by Akdede and King (2006) is also location specific.

Grisolía and Willis $(2011,2012)$ started with a broader division of repertoire classification and the types of plays indicated by the attendees of focus groups merged on the stage of the construction of econometric models. Finally, they used only three categories: "comedy", "drama" and 
Tab. 1: Type of play and similar taxonomies. Literature review

\begin{tabular}{|c|c|c|}
\hline Study & Category & Taxonomy \\
\hline Throsby (1990) & Repertoire classification & $\begin{array}{l}\text { Written before } 1900 \text { ("classic") } \\
\text { Written after } 1900 \text { by a well-known author } \\
\text { Written after } 1900 \text { by a little-known or unknown author } \\
\text { Entertainment, revue, musical }\end{array}$ \\
\hline $\begin{array}{l}\text { Abbé-Decarroux } \\
\text { (1994) }\end{array}$ & Repertoire classification & $\begin{array}{l}\text { "Classic" play (written before 1900) } \\
\text { "Modern" play (written after } 1900 \text { - deceased author) } \\
\text { "Contemporary" play (written after } 1900 \text { - living author) } \\
\text { "Atypical" play (circus, revue, collective creation, etc.) }\end{array}$ \\
\hline Urrutiaguer (2002) & Repertoire classification & $\begin{array}{l}\text { "Classics": author died before } 1900 \\
\text { Plays written before } 1980 \text { by an author who died in the 20th century } \\
\text { Plays written in French by an author who is still alive, and those written in French by } \\
\text { an author who is now dead, but published after } 1980 \\
\text { Plays written in a foreign language by an author belonging to the contemporary category }\end{array}$ \\
\hline $\begin{array}{l}\text { Corning and Levy } \\
\text { (2002) }\end{array}$ & Genre & $\begin{array}{l}\text { Comedy } \\
\text { Drama } \\
\text { Musical } \\
\text { Shakespeare } \\
\text { Tommy }\end{array}$ \\
\hline \multirow[t]{2}{*}{$\begin{array}{l}\text { Willis and Snowball } \\
\text { (2009) }\end{array}$} & Genre & $\begin{array}{l}\text { Classic } \\
\text { Modern known playwright } \\
\text { Modern unknown playwright }\end{array}$ \\
\hline & Production type & $\begin{array}{l}\text { Comedy } \\
\text { Drama } \\
\text { Musical }\end{array}$ \\
\hline $\begin{array}{l}\text { Grisolía and Willis } \\
(2011,2012)\end{array}$ & $\begin{array}{l}\text { Repertoire classification/type of } \\
\text { a play }\end{array}$ & $\begin{array}{l}\text { Comedy } \\
\text { Drama } \\
\text { Modern experimental/adaptation of a classic play }\end{array}$ \\
\hline \multirow[t]{3}{*}{$\begin{array}{l}\text { Grisolía and Willis } \\
\text { (2016) }\end{array}$} & Type of play & $\begin{array}{l}\text { Drama } \\
\text { Comedy } \\
\text { Musical } \\
\text { Opera }\end{array}$ \\
\hline & Context & $\begin{array}{l}\text { Written before } 1900 \\
\text { Written after } 1900 \\
\text { Royal Shakespeare Company }\end{array}$ \\
\hline & Type of production & $\begin{array}{l}\text { Modern } \\
\text { Traditional }\end{array}$ \\
\hline $\begin{array}{l}\text { Wiśniewska and } \\
\text { Czajkowski (2017) }\end{array}$ & & $\begin{array}{l}\text { Entertainment } \\
\text { Drama } \\
\text { Children's } \\
\text { Experimental }\end{array}$ \\
\hline
\end{tabular}

"modern experiments/adaptation[s] of a classic play", all statistically significant and positively contributing to the utility estimated in CE. The adaptation of a known piece is also used as a separate, however insignificant, binary variable in the study of the demand for Flemish theatre (Werck \& Heyndels, 2007). The last SP-based valuation in performing arts (Wiśniewska \& Czajkowski, 2017) developed a simple division into comedy and tragedy ("entertainment" and "drama", respectively) with two categories: "children's" and "experimental", all categories being statistically significant determinants of the WTP for the broader accessibility of theatres in 
Warsaw, Poland, when included in the hypothetical programme of performances' supply. The division into four categories is rooted in the local context. It turned out to be easily understandable for respondents of the survey underlying the study, as well as recognisable for policy-makers. It "offers a simple way to differentiate theatres that aim at entertainment, classical repertoire, the youngest audience or experimental forms" (p. 5).

\subsubsection{Comprehensive list of criteria}

The use of the quality characteristics of performing arts hitherto defined in the literature is limited. Throsby (1990) enumerated the criteria of quality judgements gathered into five categories:

- source material (i.e. repertoire classification and recognition of the author of the play),

- technical factors (i.e. standard of performance, production, design and house),

- benefits to the audience (e.g. entertainment or intellectual stimulation),

- benefits to the society (e.g. promotion of social evaluation and cultural preservation) and

- benefits to the art form (e.g. innovation and training of artists).

To date, there has been no well-established list of the benefits that theatre brings to its viewers, society or art itself, both in cultural economics and theatre studies. The reason is most certainly the fact that it is a very delicate matter, but also the heterogeneity of theatre itself. Once the list was formulated, Throsby never exploited it fully, but its source material and technical factors continued in many studies. The most interesting, from the valuation point of view, are the final sets of criteria: benefits to the audience, the society and the art form. Audience benefits, together with two foregoing criteria "are of most direct relevance and are certainly likely to predominate in the private demand decisions of consumers" (p. 166). Benefits to the society and benefits to the art form indicate the social dimension of performing arts' existence and operation and, therefore, "are likely to play an important role in choices made by funding bodies" (ibid.).

\subsection{Quality characteristics of cultural heritage}

Cultural heritage is the purest example of public good within cultural goods and services; it is often non-marketable and is available to the wider public by definition and political pursue, and so is the most obvious subject for non-market valuation studies. In comparison with the valuation of performing arts presented previously, these studies deliver a more comprehensive view on the cultural sector. Research includes a wide range of cultural heritage objects and institutions: all museums in Quebec, Canada (Martin, 1994); sets of historical buildings located in five areas of Grainger Town in Newcastle, UK (Garrod, Willis, Bjarnadottir, \& Cockbain, 1996); up to one hundred shipwrecks; submerged maritime cultural resources (Whitehead \& Finney, 2003); a broad range of marble monuments in Washington, DC, USA (Morey \& Rossmann, 2003) and four cultural heritage sites in Armenia (Alberini \& Longo, 2006). Some of them have provided researchers with an attempt to compare the site with similar valuation locations in other places, thus, at least theoretically, enabling the generalisation of the results: Sanz, Herrero and Bedate (2003) in their study about the National Museum of Sculpture in Valladolid, Spain, or Báez-Montenegro, Bedate, Herrero and Sanz (2012) in their valuation of cultural heritage in Valdivia, Chile, compared with other studies devoted to the Global South.

On the other hand, the hypothetical situation to be valued is sometimes limited to a simple choice between the availability of the status quo (that requires constant subsidies) or its loss; Sanz et al. (2003) estimated individuals' willingness to accept the closure of the National Museum of Sculpture in Valladolid. Choi et al. (2010) revealed the willingness to accept the limitations of the provision of cultural heritage represented by the Old Parliament House in Canberra, Australia. The potential loss of the current level of subsidies for historical buildings and monuments in Napoli, Italy, was evaluated by Santagata and Signorello (2000). Del Saz Salazar and Montagud Marques (2005) presented the opposite strategy in their evaluation of the shift from the status quo of no cultural heritage to gaining an entire 
piece of cultural heritage: the old Arab Tower in Spain that needed restoration from scratch.

The quality discussed in non-market valuation studies devoted to cultural heritage mostly refers to the quality of the provision or quality of experience. Congestion can strongly limit the quality of a museum visit. Maddison and Foster (2003) estimated that the increase in the number of visitors to the British Museum by one causes the drop in visitors' WTP for a visit by 0.05 pence. Air pollution damages historical buildings and monuments, which results in the need for regular restoration. Morey and Rossmann (2003) evaluated preservation programmes for monuments in Washington, DC, and distinguished how they are affected in an air pollution injury timeline (increased by $25 \%, 50 \%$ or $100 \%)$. The multi-attribute description of Galleria Borghese by Mazzanti (2003) mostly referred to the provision of the exhibition (visiting hours and additional services, e.g. interactive presentation of a collection). It also included the level of conservation and restoration activity, which is largely related to the quality of a collection itself, and temporal exhibitions, which can be interpreted as a zero-one availability of a given additional quality of cultural heritage (with significant positive result for both attributes). Alberini and Longo (2006) set out a similar list of provision attributes for cultural heritage sites in Armenia: (1) the enhancement of cultural experience (delivery of interpretive materials, creation of a small museum by cultural heritage sites), (2) infrastructure improvements (repairing local roads, bathrooms and rest facilities, waste management) and (3) tourism-related services (restaurants, cafes, shops, tourism information). Limitations in facilities turned out to be the most severe potential loss in utility for Australian inhabitants valuing the Old Parliament House, even though the study also included attributes more related to the quality of the cultural heritage itself (e.g. relation of original to replicas displayed where the display of replicas meant a lower quality of experience but higher conservation level), with insignificant results.

Lundhede, Bille and Hasler (2013) provided one of the most interesting findings in their study of a wetland restoration project that aimed to preserve archaeological artefacts from Stone Age villages, which presently are buried within the topsoil. The project includes two types of possible advantages for inhabitants of Denmark: the protection of biodiversity (an environmental angle) and the protection of ancient artefacts (a cultural angle). Even though biodiversity is an attribute that could be experienced by people during recreational visits and protected artefacts were neither visible nor usable by the current generation (there is only a chance that in the future they could be moved to a museum), hidden cultural heritage is valued higher (regardless of the level of protection) than recreational opportunities.

Owing to a general lack of quality measures for cultural heritage, authors try to familiarise respondents with non-market valuation surveys by supplying a notion of the quality of goods by indicating their location. For Alberini and Longo (2006), it was enough to simply ask respondents about recognisable cultural heritage sites with the use of their names: Garni, Haghardzin, Khor Virap and Tatev (especially understandable for on-site surveys). A similar strategy was used by Garrod et al. (1996) who defined the hypothetical programme of renovating historical buildings by including five areas in Grainger Town that differed in terms of their richness of cultural heritage and the condition of the heritage; the place itself was the quality.

\subsection{Quality characteristics in the other fields of culture}

Finn, McFadyen and Hoskins (2003) estimated the value of the Canadian Broadcasting Corporation's programming policies. The research questions regarded preferences towards Canadian vs. foreign programmes and local vs. national news. The division into different kinds of TV programmes was used as a list of attributes in the econometric model (including children's programmes, Canadian drama and film, national news and local news, among others). Nearly all the categories contributed to the value of TV broadcasting availability, with sports, Canadian drama and film and national news having the biggest impact. This strategy of describing the qualitative features of a cultural good is similar to those undertaken in the valuation of performing arts.

An early study by Randall, Ives and Eastman (1974) is not even assigned to cultural economics but was written during the creation of the discipline. However, as long as it treats aesthetic damages, it delivers a very early (and 
successful) way of including aesthetic attributes into non-market valuation research. The authors estimated the benefits of the abatement of aesthetic environmental damages associated with the four corners of the steam electric generating plant (at the Navajo Mine in Fruitland, New Mexico); a hypothetical scenario detailed three possible states of damages and was accompanied by visual material. Visual material also presents possible states of renovation of the plaza in Belfast (Alberini, Riganti, \& Longo, 2003). The prospects are supported by detailed definitions of major characteristics of the urban site: the height of the buildings around the plaza (the same or higher than at the time of the study), the relative amount of open space in relation to built space (no change or $\pm 50 \%$ ) and split between residential and retail usage (possible options: 50/50, 25/75, 75/25). All the attributes turned out to be statistically significant with a greater residential usage of the space and increase in open space having a positive impact and higher buildings having a negative impact. In cases of physical objects, very precise descriptions are possible and worth including. Both articles demonstrated the successful use of visual material to indicate the quality of cultural or aesthetic goods. It is easier in cases of physical objects but should be taken into consideration when intangible and more ephemeral goods are valued, particularly if the survey is run with the use of technical devices enabling not only the presentation of pictures but also sound and video, which could help viewers to understand, e.g., the nature of performing arts.

\subsubsection{Quality metrics}

The use of the quality characteristics of art and culture in non-market valuation studies is rooted in a broader discussion about quality judgements and measurements in aesthetics as well as cultural policy. Artists, scientists and policy-makers negotiate the value of art and culture. A lot of this value lies "beyond price", as the title of the book by Hutter and Throsby (2008) announces. This discourse brings with it a more descriptive way of including quality into scientific research. For example, Behr, Brennan and Cloonan (2016) tried to understand the act of valuing diverse live music events in Queen's Hall in Edinburgh by the audience. Not surprisingly, they found that the cost of an event influences only the decision of whether to attend. Once individuals do decide to attend, an event can meet the threshold of their expected quality or not. There is no "good price" for the experience below this threshold and no sense to discuss it. If the event exceeds the threshold, the experience is usually recognised as "good value for money", regardless of what the cost was. Therefore, the valuation process is closely connected to quality characteristics. Authors define the features that can be valuable and joyful with the use of verbal descriptions: intimacy vs spectacle; unique atmosphere and character of the venue; predictable, smooth and comfortable running of the show; the possibility of surprise and the unexpected; enjoyment of confirmation of already held tastes; becoming immersed; inward participation and outward physical participation. As Behr, Brennan and Cloonan concluded: "Our respondents were clear that they went to music to forget about monetary concerns and to have a transcendent experience" (p. 416).

In the age of sophisticated measurements of the impact of public policies in different sectors, for which the cost-benefit analysis dominance in the evaluation of cultural policies is just a manifestation, policy-makers work hard on the quality measurements of arts and culture. Two projects are the effect of this work: "The Public Value Measurement Framework - Measuring the Quality of the Arts" (Government of Western Australia, 2014) and "Quality Metrics - Measuring Quality in the Cultural Sector" run by Arts Council England (Knell \& Whitaker, 2016). Both aimed to find an expression for a quality dimension that would be relevant for all: artists themselves (for self-evaluation); peers, i.e. people from the art world, and the public. Conducted separately, but in a similar Anglo-Saxon cultural context, the projects brought similar lists of quality dimensions gathered in Table 2.

The idea of the projects was "to produce data and insights that not only tell a better story [...] of the full value of arts and cultural activities to the public, but which is also regarded as relevant, credible and useful to artists and cultural practitioners across the State to plan and develop their practice" (Government of Western Australia, 2014, p. 4). The projects were run across different cultural sectors that promised potential comparisons between art forms. However, 
the operationalisation of the quality dimensions found is questionable. Bille and Olsen (2018) put forward the problem of applying static indicators in dynamic art. Consequently, indicators consolidate the existing understandings of quality, as opposed to being a tool for judging novelty. It is also possible that "a work of art can be extremely distinctive and original and still be a rubbish - uninteresting, incoherent, simply of low quality" (Bille \& Olsen, 2018, p. 243) - distinctiveness and originality can have nothing in common with quality. It also seems that indicators are more suitable for professional critics than the general public, as assessments by peers exhibit greater variation, while the assessments of the public do not fluctuate much: "audiences are evaluating their general satisfaction with the cultural experience rather than its quality in relation to specific parameters" (ibid, p. 245). Still, the list of quality dimensions and the list of benefits invented by Throsby (1990), presented in previous sections, can serve as an outline for descriptions of cultural goods to be valued.

\section{Summary}

A fairly short history of the non-market valuation of cultural goods delivers quite a long bibliography of the usage of quality measurements and indicators that served to convey the nature of the good. However, their plausibility, understandability and meaningfulness to respondents of questionnaires are questionable, as well as their relevance for econometric models (underlying non-market valuation), theoretical requirements and policy-making.

First of all, it seems particularly difficult to find a common way to express quality for different cultural phenomena. Two major kinds of cultural goods appear: (1) ephemeral, timely and delivering diverse products i.e. performing arts and the like (broadcasting, film) and (2) cultural heritage, which is given as a whole and does not change over time.

Current studies devoted to performing arts developed the understanding of demand and a number of quality determinants of their valuation by society; however, most of the variables used to capture quality leave much to desire. The significance of measurements created on the basis of supply-side data is vague. The
Tab. 2: Quality dimensions from two projects

\begin{tabular}{|c|c|}
\hline Quality dimension & Description \\
\hline Relevance (A/E) & $\begin{array}{l}\text { It had something to say about today's } \\
\text { world/the world in which we live }\end{array}$ \\
\hline Captivation (A/E) & It was absorbing and held my attention \\
\hline Originality (A/E) & It was ground-breaking \\
\hline Distinctiveness (A/E) & $\begin{array}{l}\text { It was different from things I have } \\
\text { experienced before }\end{array}$ \\
\hline Excellence - global (A/E)* & $\begin{array}{l}\text { It was amongst the best of its type [in } \\
\text { the world] }]^{*} \text {. }\end{array}$ \\
\hline Excellence - local (A/E)* & $\begin{array}{l}\text { It was amongst the best of its type [in } \\
\text { Australia]* }\end{array}$ \\
\hline Risk (A/E) & $\begin{array}{l}\text { The artists/curators really challenged } \\
\text { themselves with this }\end{array}$ \\
\hline Rigor (A/E) & $\begin{array}{l}\text { It seemed well thought through and put } \\
\text { together }\end{array}$ \\
\hline Presentation $(\mathrm{E})$ & It was well produced and presented \\
\hline Challenge (E) & It was thought-provoking \\
\hline Enthusiasm (E) & $\begin{array}{l}\text { I would come to something like this } \\
\text { again }\end{array}$ \\
\hline Local impact (E) & It is important that it is happening here \\
\hline Concept (E) & It was an interesting idea \\
\hline
\end{tabular}

* A - Australian project, E - English project. Division into global and local excellence appears only in the Australian list of quality dimensions; the English quality dimension is simply 'excellence'. Source: Government of Western Australia (2014) and Knell and Whitaker (2016).

most important variables (both in significance and value), those based on ex-post subjective opinions (reviews, words of mouth and recognition of artists), have limited utility for cultural policies. There is little chance to determine the evaluation of productions, either by experts or viewers, of the future programme for theatre repertoire. Conditioning ex ante subsidies for theatres on future reviews or word of mouth is highly risky. What can help are the determinants of positive opinions rather than the opinions themselves. Therefore, the inherent features of performances rather than the perception of performances could better serve policymaking.

Repertoire classification, which seems to be the most influential quality characteristic of a performance, serves only as an indicator of preferences towards a sad or happy content and suffers from the necessity of 
adjusting to the local cultural context. However, a simple division into performance types seems to remain the best compromise between simplicity (to be understandable for respondents) and objectivity (to be usable for policymakers). The inclusion of more venues into the studies can be a way to overcome local contexts, as a lesson from cultural heritage studies delivers. When the offer includes diverse products, it is worth checking their contribution to the value of a cultural venue or service. The positive value of all types of products should not surprise. It would be surprising, however, if a theatre, music hall or broadcasting company delivered the offer of no value for people. It is the relationship between the value of products with different quality characteristics that is interesting.

The lists of criteria defined by Throsby, as well as quality dimensions from projects like "Quality Metrics", can be used to specify the merit characteristics of theatre performances. They can help respondents from different backgrounds (audiences, artists and stakeholders) to verbally communicate. In their connections to different types of cultural products, their use can demonstrate the crucial dimensions of quality for diverse goods.

Cultural heritage largely consists of real, physically located objects. Their quality does not differ much with the passing of time. What can differ is the quality of provision and experience. Therefore, the studies focussed on these aspects of the quality of cultural heritage, leaving the quality of the objects unevaluated. What is more, non-market valuation studies of cultural heritage deliver experience with the use of visual materials as a tool to indicate qualitative characteristics, a well-established practice in other fields of economic research (e.g. environmental economics). They could be used more broadly in cultural economics, perhaps alongside audio-visual content, which is easily available for respondents in a time when electronic devices are used to support interviews with respondents.

Even the limited use of quality variables in up-todate SP-based non-market valuations enables the formulation of some policy recommendations, albeit they are mostly limited to a particular institution. Throsby (1990) noticed high heterogeneity among visitors of different venues, which resulted in different elasticities of the demand. He also advised theatres to pay particular attention to quality when venues aimed to increase audience numbers. Willis and Snowball (2009) found econometric evidence for demand heterogeneity, which is interpreted in terms of omnivore taste (Peterson, 1992), and support in general the current policy of the festival researched. Grisolía and Willis (2011) found word of mouth to be as important as reviews. They also delivered the valuation of performances with different levels of reviewer judgements and play genres. This might serve as a source for directions on how to build a repertoire for a theatre manager (marketing decisions); however, he or she has little impact on reviews. The subsequent study (Grisolía \& Willis, 2012) developed an investigation into the heterogeneity of viewers with the use of a latent class model. Some recommendations for public policy consider the engagement of a younger generation, which mostly constitutes the latent class called "popular": small and focussed on entertainment. A subsequent study on the Royal Theatre in Newcastle (Grisolía \& Willis, 2016) justified public support for the Royal Shakespeare Company and showed significant differences in peoples' WTP for different types of play, with drama being the most valuable. The study by Wiśniewska and Czajkowski (2017) supported an increase in the provision of discounted theatre tickets (a quasi-public good), particularly in venues that specialised in experimental, children's and drama performances. The authors noted that the passive-use values of theatre recognised by the Society of Warsaw could be a reason for the difference between theatregoers' preferences for subsidy distribution and audience ticketbuying behaviour.

Non-market valuations of cultural heritage deliver simpler yes-no answers to the questions regarding the justification of public expenditure on particular sites or objects (however, the way the hypothetical scenario is expressed is far from the current state-of-the-art non-market valuation guidelines). Moreover, policymakers, managers and cultural heritage venues obtain knowledge of the consequences of possible changes in the provision of goods (including the level of restoration and conservation).

The problem with conveying the nature of the good in a plausible, understandable and meaningful way lies not only in art and culture itself, nor researchers' abilities to express it, but in the cultural experiences of the general public. The problem with experience is stronger than in 
other markets due to the experiential way of acquiring cultural goods. There is a risk that people who do not participate enough are not sufficiently informed of how the good is described. The way to solve the problem may be in accepting the good-enough informed preferences instead of fully informed preferences. Still, the better the expression of the quality of cultural goods we achieve, the better-informed preferences will be.

\section{Acknowledgements}

I am grateful to Trine Bille and Monika Murzyn-Kupisz for careful revisions of the article, helpful comments and advises that significantly improved the quality of this article.

\section{Funding}

The study was funded from the PRELUDIUM research grant of the National Science Centre of Poland (project 2014/15/N/HS4/01441).

\section{References}

[1] Abbé-Decarroux, F. (1994). The perception of quality and the demand for services. Journal of Economic Behavior \& Organization, 23(1), 99-107.

[2] Akdede, S. H., \& King, J. T. (2006). Demand for and productivity analysis of Turkish public theater. Journal of Cultural Economics, 30(3), 219-231.

[3] Alberini, A., \& Longo, A. (2006). Combining the travel cost and contingent behavior methods to value cultural heritage sites: Evidence from Armenia. Journal of Cultural Economics, 30(4), 287304.

[4] Alberini, A., Riganti, P., \& Longo, A. (2003). Can people value the aesthetic and use services of urban sites? Evidence from a survey of belfast residents. Journal of Cultural Economics, 27(3-4), 193-213.

[5] Arrow, K., Solow, R., Portney, P. R., Leamer, E. E., Radner, R., \& Schuman, H. (1993). Report of the NOAA panel on contingent valuation. Federal Register, 58(10), 4601-4614.
[6] Báez, A., \& Herrero, L. C. (2012). Using contingent valuation and cost-benefit analysis to design a policy for restoring cultural heritage. Journal of Cultural Heritage, 13(3), 235-245.

[7] Báez-Montenegro, A., Bedate, A. M., Herrero, L. C., \& Sanz, J. Á. (2012). Inhabitants' willingness to pay for cultural heritage: A case study in Valdivia, Chile, using contingent valuation. Journal of Applied Economics, 15(2), 235-258.

[8] Bakhshi, H., Fujiwara, D., Lawton, R., Mourato, S., \& Dolan, P. (2015). Measuring economic value in cultural institutions. Swindon, Wiltshire: Arts and Humanities Research Council.

[9] Bateman, I. J., Carson, R. T., Day, B., Hanemann, M. W., Hanley, N., Hett, T., 1/4 Swanson, J. (2004). Economic valuation with stated preference techniques: A manual. Northampton, MA: Edward Elgar.

[10] Baumol, W. J., \& Bowen, W. G. (1966). Performing arts - The economic dilemma. New York, NY: The Twentieth Century Fund.

[11] Beardsley, M. (1958). Aesthetics: Problems in the philosophy of Criticism. New York, NY: Harcourt, Brace.

[12] Bedate, A. M., Herrero, L. C., \& Sanz, J. Á. (2009). Economic valuation of a contemporary art museum: Correction of hypothetical bias using a certainty question. Journal of Gambling Studies, 25(3), 185-199.

[13] Behr, A., Brennan, M., \& Cloonan, M. (2016). Cultural value and cultural policy: Some evidence from the world of live music. International Journal of Cultural Policy, 22(3), 403-418.

[14] Bille Hansen, T. (1997). The willingness-to-pay for the royal theatre in Copenhagen as a public good. Journal of Cultural Economics, 21(1), 1-28.

[15] Bille, T., \& Baldin, A. (2017). Theater management - Quality indicators and demand. Working Paper presented at 8tth European Workshop on Applied Cultural Economics.

[16] Bille, T., \& Olsen, F. (2018). Measuring the quality and impact of arts and culture. In K. O. Eliassen, J. F. Hovden, \& Ø. Prytz (Eds.), Contested qualities. Negotiating value in arts and culture (pp. 229-256). Oslo, Norway: Vigmostad \& Bjørke AS.

[17] Carson, R. T. (2011). Contingent valuation. A comprehensive bibliography and history. Cheltenham, UK, Northampton, MA, USA: Edward Elgar. 
[18] Carson, R. T. (2012). Contingent valuation: A practical alternative when prices aren't available. Journal of Economic Perspectives, 26(4), 27-42.

[19] Carson, R. T., Flores, N. E., \& Meade, N. F. (2001). Contingent valuation: Controversies and evidence. Environmental and Resource Economics, 19(2), 173210.

[20] Champ, P. A., Boyle, K. J., \& Brown, T. C. (Eds.), (2003). A primer on nonmarket valuation. New York, NY: Springer Science+Business Media, LLC.

[21] Choi, A. S., Ritchie, B. W., Papandrea, F., \& Bennett, J. (2010). Economic valuation of cultural heritage sites: A choice modeling approach. Tourism Management, 31(2), 213-220.

[22] Colbert, F., Beauregard, C., \& Vallée, L. (1998). The importance of ticket prices for theatre patrons. International Journal of Arts Management, 1(1), 8-15.

[23] Corning, J., \& Levy, A. (2002). Demand for live theater with market segmentation and seasonality. Journal of Cultural Economics, 26(3), 217-235.

[24] Del Saz Salazar, S., \& Montagud Marques, J. (2005). Valuing cultural heritage: The social benefits of restoring and old Arab tower. Journal of Cultural Heritage, 6(1), 69-77.

[25] Dickie, G. (1988). Evaluating art. Philadelphia, PA: Temple University Press.

[26] Finn, A., Mcfadyen, S., \& Hoskins, C. (2003). Valuing the Canadian broadcasting corporation valuing the Canadian broadcasting corporation. Journal of Cultural Economics, 27(3), 177-192.

[27] Frey, B. S. (2003). Arts \& economics. Analysis \& cultural policy. Berlin Heidelberg New York, NY: Springer-Verlag.

[28] Garrod, G. D., Willis, K. G., Bjarnadottir, H., \& Cockbain, P. (1996). The Non-Priced Benefits of Renovating Historic Buildings A Case Study of Newcastle' s Grainger Town. Cities, 13(6), 423-30.

[29] Ginsburgh, V., \& Weyers, S. (2008). Quantitative approaches to valuation in the arts, with an application to movies. In D. Throsby \& M. Hutter (Eds.), Beyond price. Value in culture, economics, and the arts. New York, NY: Cambridge University Press, 179-199.

[30] Government of Western Australia. (2014). Public value measurement framework. Measuring the quality of the arts. Australia and UK : Department of Culture and the Arts Western Australia and John Knell, Intelligence Agency Ltd.

[31] Grisolía, J. M., \& Willis, K. G. (2011). An evening at the theatre: Using choice experiments to model preferences for theatres and theatrical productions. Applied Economics, 43(27), 3987-3998.

[32] Grisolía, J. M., \& Willis, K. G. (2012). A latent class model of theatre demand. Journal of Cultural Economics, 36(2), 113-139.

[33] Grisolía, J. M., \& Willis, K. G. (2016). Consumer choice of theatrical productions: A combined revealed preference - stated preference approach. Empirical Economics, 50(3), 933-957.

[34] Hensher, D. A., Rose, J. M., \& Greene, W. H. (2005). Applied choice analysis: A primer. Cambridge, England: Cambridge University Press.

[35] Hess, S., \& Daly, A. (Eds.), (2014). Handbook of choice modelling. Northampton, MA: Edward Elgar.

[36] Hutter, M., \& Throsby, D. (Eds.), (2008). Beyond price. value in culture, economics, and the arts. New York, NY: Cambridge University Press.

[37] Kanninen, B. J. (Ed.). (2007). Valuing environmental amenities using stated choice studies. A common sense approach to theory and practice. Dordrecht, Netherlands: Springer.

[38] Knell, J., \& Whitaker, A. (2016). Quality metrics final report. Quality metrics national test. Culture counts. UK: Arts Council England.

[39] Krebs, S., \& Pommerehne, W. W. (1995). Politicoeconomic interactions of German public performing arts institutions. Journal of Cultural Economics, 19(1), 17-32.

[40] Krutilla, J. V. (1967). Conservation reconsidered. The American Economic Review, 57(4), 777-786.

[41] Lancester, K. J. 1966. A new approach to consumer theory. Journal of Political Economy, 74(2), 132-157.

[42] Lloyd-Smith, P., Zawojska, E., \& Adamowicz, W. (2018). Moving beyond the CV versus CE - Presentation effects in stated preference. Faculty of Economic Sciences Working Paper Series 14.

[43] Lundhede, T., Bille, T., \& Hasler, B. (2013). Exploring preferences and non-use values for hidden archaeological artefacts: A case from Denmark. International Journal of Cultural Policy, 19(4), 501-530. 
[44] Maddison, D., \& Foster, T. (2003). Valuing congestion costs in the British museum. Oxford Economic Papers, 55(1), 173-190.

[45] Martin, F. (1994). Determining the size of museum subsidies. Journal of Cultural Economics, 18(4), 255270.

[46] Mazzanti, M. (2002). Cultural heritage as multidimensional, multi-value and multi-attribute economic good: Toward a new framework fro economic analysis and valuation. Journal of SocioEconomics, 31(5), 529-558.

[47] Mazzanti, M. (2003). Valuing cultural heritage in a multi-attribute framework microeconomic perspectives and policy implications. Journal of Socio-Economics, 32(5), 549-569.

[48] Morey, E., \& Rossmann, K. G. (2003). Using statedpreference questions to investigate variations in willingness to pay for preserving marble monuments: Classic heterogeneity, random parameters, and mixture models. Journal of Cultural Economics, 27(3-4), 215-229.

[49] Morrison, W. G., \& West, E. G. (1986). Subsidies for the performing arts: evidence on voter preference. Journal of Behavioral Economics, 15(3), 57-72.

[50] Mourato, S., \& Mazzanti, M. (2002). Economic valuation of cultural heritage: Evidence and prospects. In M. de la Torre (Ed.), Assessing the values of cultural heritage (pp. 51-76). Los Angeles, CA: The Getty Conservation Institute.

[51] Noonan, D. (2002). Contingent valuation studies in the arts and culture: An annotated bibliography. The Cultural Policy Center at the University of Chicago Working Paper Series.

[52] Noonan, D. S. (2003). Contingent valuation and cultural resources: A meta-analytic review of the literature. Journal of Cultural Economics, 27, 1-24.

[53] O'Brien, D. (2010). Measuring the value of culture: A report to the department for culture media and sport. London.

[54] O'Hagan, J., \& Zieba, M. (2010). Output characteristics and other determinants of theatre attendance - An econometric analysis of German data. Applied Economics Quarterly, 56(2), 147-174.

[55] Organisation for Economic Co-operation and Development. (2006). Cost-benefit analysis and the environment: Recent developments. Paris, France.
[56] Papandrea, F. (1999). Willingness to pay for domestic television programming. Journal of Cultural Economics, 23, 149-166.

[57] Peterson, R. (1992). Understanding audience segmentation: From elite and mass to omnivore and univore. Poetics, 21, 243-258.

[58] Randall, A., Ives, B., \& Eastman, C. (1974). Bidding games for valuation of aesthetic environmental improvements. Journal of Environmental Economics and Management, 1(2), 132-149.

[59] Santagata, W., \& Signorello, G. (2000). Contingent valuation and cultural policy design: The case of 'Napoli Musei Aperti.' Journal of Cultural Economics, 24, 181-204.

[60] Sanz, J. A., Herrero, L. C., \& Bedate, A. M. (2003). Contingent valuation and semiparametric methods: A case study of the national museum of sculpture in Valladolid, Spain. Journal of Cultural Economics, 27(3-4), 241-257.

[61] Schwarz, N., \& Sudman, S. (1992). Context effects in social and psychological research. New York, NY: Springer-Verlag.

[62] Snowball, J. D. (2005). Art for the masses? Justification for the public support of the arts in developing countries - Two arts festivals in South Africa. Journal of Cultural Economics, 29(2), 107-125.

[63] Snowball, J. D. (2008). Measuring the value of culture - Methods and examples in cultural economics. Berlin Heidelberg: Springer-Verlag.

[64] Tobias, S. (2004). Quality in the performing arts: Aggregating and rationalizing expert opinion. Journal of Cultural Economics, 28(2), 109-124.

[65] Throsby, C. D. (1990). Perception of quality in demand for the theatre. Journal of Cultural Economics, $14(1), 65-82$.

[66] Throsby,D. (1994). The production and consumption of the arts: A view of cultural economics. Journal of Economic Literature, 32(1), 1-29.

[67] Throsby, D. (2001). Economics and culture. Cambridge, England: Cambridge University Press.

[68] Throsby, D. (2003). Determining the value of cultural goods: How much (or HowLittle) does contingent valuation tell us? Journal of Cultural Economics, 27, 275-285. 
[69] Throsby, D., \& Withers, G. A. (1979). The economics of the performing arts. New York, NY: St. Martin's Press.

[70] H.M. Treasury. (2018). The green book. Central government guidance on appraisal and evaluation. London, UK: OGL Press.

[71] Tuan, T. H., \& Navrud, S. (2007). Valuing cultural heritage in developing countries: Comparing and pooling contingent valuation and choice modelling estimates. Environmental and Resource Economics, 38(1), 51-69.

[72] Urrutiaguer, D. (2002). Quality judgements and demand for French public theatre. Journal of Cultural Economics, 26(3), 185-202.

[73] US Office of Management and Budget. (1992). Circular No. A-94 Revised (Transmittal Memo No. 64). Washington, DC.

[74] Werck, K., \& Heyndels, B. (2007). Programmatic choices and the demand for theatre: The case of Flemish theatres. Journal of Cultural Economics, 31(1), 25-41.

[75] Whitehead, J. C., \& Finney, S. S. (2003). Willingness to pay for submerged maritime cultural resources. Journal of Cultural Economics, 27(3-4), 231-240.

[76] Willis, K. G., \& Snowball, J. D. (2009). Investigating how the attributes of live theatre productions influence consumption choices using conjoint analysis: The example of the national arts festival, South Africa. Journal of Cultural Economics, 33(3), 167-183.

[77] Wiśniewska, A., \& Czajkowski, M. (2017). Designing a socially efficient cultural policy: The case of municipal theaters in Warsaw. International Journal of Cultural Policy, doi:10.1080/10286632.201 7.1308504.

[78] Wittgenstein, L. (1958). Philosophical investigations. New York, NY: Macmillan.

[79] Zieba, M. (2009). Full-income and price elasticities of demand for German public theatre. Journal of Cultural Economics, 33(2), 85-108.

[80] Zieba, M. (2011). An analysis of technical efficiency and efficiency factors for Austrian and Swiss non-profit theatres. Swiss Journal of Economics and Statistics, 147(1998), 233-274. 